Check for updates

Cite this: RSC Adv., 2019, 9, 2026

\title{
Photostability and photocatalytic degradation of ionic liquids in water under solar light $\uparrow$
}

\author{
Jorge Bedia, (D)* Juan José Rodriguez, Daniel Moreno, José Palomar \\ and Carolina Belver (D)
}

\begin{abstract}
The aim of this work is to study, (i) the photostability of different imidazolium and pyridinium ionic liquids (ILs) in water under solar light; and (ii) the photocatalytic degradation of those ILs in water with $\mathrm{TiO}_{2}$ under solar light. The effects of the type of cation and anion as well as the length of the cationic chain of the imidazolium ILs have been analyzed. These imidazolium-based ILs show high solar stability, slightly decreasing as the length of the cationic chain increases. The anion plays a main role in the stability of ILs under solar light, decreasing in the case of hydrophobic anions. The kind of head group (pyridinium or imidazolium) or the presence of functional groups (allyl, OH) also influence the solar light stability. DFT calculations on the fundamental and excited electronic states of the ILs were carried out to obtain a deeper insight on their photostability. In the case of the photocatalytic degradation of the ILs, complete conversion was achieved for all the ILS tested but mineralization reached $80 \%$ at the most. The rate of degradation increased with the length of the alkyl chain while the anion showed little effect. The pyridinium-based IL tested was the easiest to breakdown.
\end{abstract}

Received 21st September 2018 Accepted 10th January 2019

DOI: $10.1039 / c 8 r a 07867 j$

rsc.li/rsc-advances different alternatives have been investigated, mainly based on adsorption and catalytic processes. Adsorption of ILs has been studied with different materials, such as, activated carbons, ${ }^{\mathbf{9 - 1 2}}$ resins,${ }^{13,14}$ aluminium-based salts, ${ }^{15}$ clays $^{16}$ or zeolites. ${ }^{17}$ The amount of IL adsorbed can be increased by modifying the surface of the adsorbent. For instance, activated carbons with high content of polar groups are more efficient for adsorbing hydrophilic ILs due to adsorbate-adsorbent hydrogen bonding. On the opposite, heat-treated activated carbons, with very low content of surface oxygen groups are preferred for the removal of hydrophobic ILs. ${ }^{18}$ On the other hand, Advanced Oxidation Processes (APOs) are powerful methods for the removal of water pollutants upon "in situ" generation of strong oxidizing radicals. These methods include ultrasonic ${ }^{19}$ and electrolytic degradation $^{20,21}$ as well as some other well-known and more widely used technologies like different Fenton-based systems. Conventional Fenton process, ${ }^{22-25}$ sono-Fenton ${ }^{26-28}$ or electroFenton $^{29-31}$ have been studied for ILs breakdown. Photocatalytic oxidation uses a semiconductor that can be excited by photons generating electron-hole pairs. These charges can interact at the surface of the photocatalyst with adsorbed compounds yielding radical species able to induce redox reactions. Photocatalytic processes have been scarcely investigated for ILs degradation. Stepnowski and Zaleska ${ }^{32}$ compared different photo-assisted oxidation processes, namely $\mathrm{UV}, \mathrm{UV} / \mathrm{H}_{2} \mathrm{O}_{2}$ and $\mathrm{UV} / \mathrm{TiO}_{2}$, for the degradation of imidazolium ILs. They concluded that the greatest degradation efficiency was achieved by $\mathrm{UV} / \mathrm{H}_{2} \mathrm{O}_{2}$. Morawski et $a .^{33}$ analysed the photocatalytic degradation under UV light in the presence of $\mathrm{TiO}_{2}$ of different
Departamento de Ingeniería Química, Facultad de Ciencias, Universidad Autónoma de Madrid, C/Francisco Tomas y Valiente 7, 28049 Madrid, Spain. E-mail: Jorge.bedia@ uam.es; Tel: +34-91-497-29-11

$\dagger$ Electronic supplementary information (ESI) available. See DOI: $10.1039 / \mathrm{c} 8 \mathrm{ra07867j}$ 
types of ILs, including imidazolium, ammonium, phosphonium and pyridinium. The work concluded that the degradation rate depends on the cation and anion of the IL, being the ILs with lower molar mass the most stable. Furthermore, phosphonium ILs seem the easiest to decompose under UV irradiation. Finally, Itakura et $a .^{34}$ studied the decomposition of imidazolium based ILs using $\mathrm{Pt}-\mathrm{TiO}_{2}$ and $\mathrm{TiO}_{2}$ photocatalysts under UV light. They achieved high cation degradations, but the anions were more resistant and needed an additional hydrothermal treatment with $\mathrm{Ca}(\mathrm{OH})_{2}$. However, to the best of our knowledge, neither the stability not the photocatalytic degradation of ILs in aqueous solution under solar light have been studied in the literature so far. Recently, Calza et al. ${ }^{35}$ reported on the photocatalytic degradation of pyridinium-based ionic liquids in water but under UV irradiation. They analysed the effect of the length of the alkyl chain, the kind of inorganic anion and the type of substituents. The nature of the anion deeply affected the transformation pathways and the extent of mineralization.

The aim of the current work is to study, (i) the photostability of different ILs in water under solar light, a crucial issue regarding potential applications; and (ii) the photocatalytic degradation of ILs in water with $\mathrm{TiO}_{2}$ under solar light. Eight different ILs have been tested in this study. DFT calculations on the fundamental and excited electronic states of the ILs were carried out in order to obtain a deeper insight on their photostability. The work analyses the effects of the cations (alkyl chain length, head group, functional groups) and anions of the ILs on their breakdown and mineralization.

\section{Experimental}

\section{Materials}

1-Ethyl-3-methylimidazolium chloride, 1-butyl-3-methylimidazolium chloride, 1-decyl-3-methylimidazolium chloride, 1-butyl-3-methylimidazolium tetrafluoroborate, 1-butyl-3methylimidazolium tris(pentafluoroethyl)trifluorophosphate, 1-allyl-3-methyl-imidazolium chloride, 1-(2-hydroxyethyl)-3methylimidazolium chloride and 1-butyl-4-methylpyridinium chloride were the ILs selected for the study. Table 1 summarizes the nomenclature, molar mass and molecular structure of these ILs. Most of them are imidazolium-based ILs with different lengths of the cationic alkyl chain ([Emim], [Bmim] and [Dcmim]), modifications of that alkyl chain by adding functional groups ([EtOHmin] and [Allylmim]) and different anions ([Cl], [FAP $]$ and $\left.\left[\mathrm{BF}_{4}\right]\right)$. Furthermore, a pyridinium-based IL has also been studied ([Bu4MePy $][\mathrm{Cl}])$. All the ILs were obtained from Sigma-Aldrich and IoLiTec and used as received.

Commercial $\mathrm{TiO}_{2}$, Aeroxide ${ }^{\circledR}$ P25 (Evonik Degussa) supplied by Sigma-Aldrich, was used as photocatalyst. This photocatalyst is commonly used in photocatalysis and its properties have been detailed in literature. ${ }^{36}$ Therefore, the characterization results are shown in ESI (Fig. S1 $\dagger$ ), together with the description of the characterization techniques. In summary, the photocatalyst contains 72 and $28 \%(\mathrm{w} / \mathrm{w})$ of anatase and rutile phases respectively, with primary particle size of around $21 \mathrm{~nm}$. The
BET surface area is $50 \mathrm{~m}^{2} \mathrm{~g}^{-1}$, and the band gap value calculated from the UV-vis DRS profile is $3.00 \mathrm{eV}$.

\section{Solar photocatalytic tests}

The photocatalytic degradation tests of the ILs under solar light irradiation were performed in Pyrex glass reactors $(500 \mathrm{~mL})$, with sampling and flowing air ports and a magnetic stirrer. The experiments were carried out in a Suntest solar simulator (Suntest XLS+, ATLAS) equipped with a Xe lamp (320-800 nm) whose details could be found elsewhere. ${ }^{37-39}$ The intensity of irradiation was fixed to $450 \mathrm{~W} \mathrm{~m}^{-2}$ in all the experiments. The reaction temperature did not overcome $35{ }^{\circ} \mathrm{C}$. Two types of tests were performed, (i) photolysis tests, in the absence of photocatalyst, to assess the stability of the different ILs under solar light, and (ii) photocatalytic tests, where $\mathrm{TiO}_{2}$ was used as photocatalyst for the degradation of the ILs. In both, the reaction volume was $300 \mathrm{~mL}$ and the initial concentration of the ILs was $20 \mathrm{mg} \mathrm{L}^{-1}$. In the photocatalytic tests, $75 \mathrm{mg} \mathrm{L}^{-1}$ of $\mathrm{TiO}_{2}$ were dispersed in the aqueous IL solution. Before each photocatalytic experiment, the suspension was stirred in dark for 2 hours to achieve the adsorption equilibrium. Subsequently, the suspension was exposed to solar irradiation for $10 \mathrm{~h}$. At given time intervals, $8 \mathrm{~mL}$ of the suspension were collected and the photocatalyst was removed by filtration using nylon fibre filters (Tecknocroma $0.45 \mu \mathrm{m}$ ).

The composition of the liquid phase was analysed by HPLC (Varian Pro-Start 310) with diode array detector (330 PDA) and an amide C16 Discovery RP Supelco column. The mobile phase consisted in a mixture of acetonitrile $(5 \% \mathrm{v})$, orthophosphoric acid $\left(430 \mu \mathrm{L} \mathrm{L}^{-1}\right)$ and disodium hydrogen phosphate $(0.71 \mathrm{~g}$ $\mathrm{L}^{-1}$ ), with a constant flow of $0.5 \mathrm{~mL} \mathrm{~min}^{-1}$. The detection wavelength for the different ILs was set according to the maximum of the UV-vis absorption spectrum (Fig. 1) recorded in an UV-vis spectrophotometer (Cary 60 UV-vis, Agilent Technologies). Total organic carbon (TOC) was measured with a Shimadzu TOC equipment and the organic acids were analysed by ionic chromatography with a Metrohm 790 Personal IC equipment.

\section{Computational details}

Ionic liquids geometries (for independent ions and ion-pair molecular models) were optimized using Gaussian v09 software $^{40}$ Optimizations were carried out using gas-phase environment and DFT calculations with $\mathrm{B}^{2} \mathrm{LYP}^{\mathbf{4 1}}$ functional and 6$311^{* *} \mathrm{G}++$ basis set. To simulate the solvent effect, additional optimizations using PCM water solvation model calculations were performed. In order to study the photochemical behaviour of ionic liquids in the excited states, TD-DFT/B3LYP/6$311++\mathrm{G}^{* *}$, absorption spectra were predicted by a single point TD-DFT calculation ${ }^{42}$ of excitation energies $\left(S_{0} \rightarrow S_{1}^{*}\right.$, etc.). In addition, the molecular structure in the first excited electronic singlet state $\left(\mathrm{S}_{1}\right)$ was optimized to obtain a minimum of energy at TD-DFT/B3LYP/6-311++G** computational level. Next, the $\mathrm{S}_{1} \rightarrow \mathrm{S}_{0}^{*}$, transition energy was calculated by single-point TD-DFT calculation using the optimized geometry in $\mathrm{S}_{1}$. Additional 
Table 1 Nomenclature, molar mass and molecular structure of the ILs

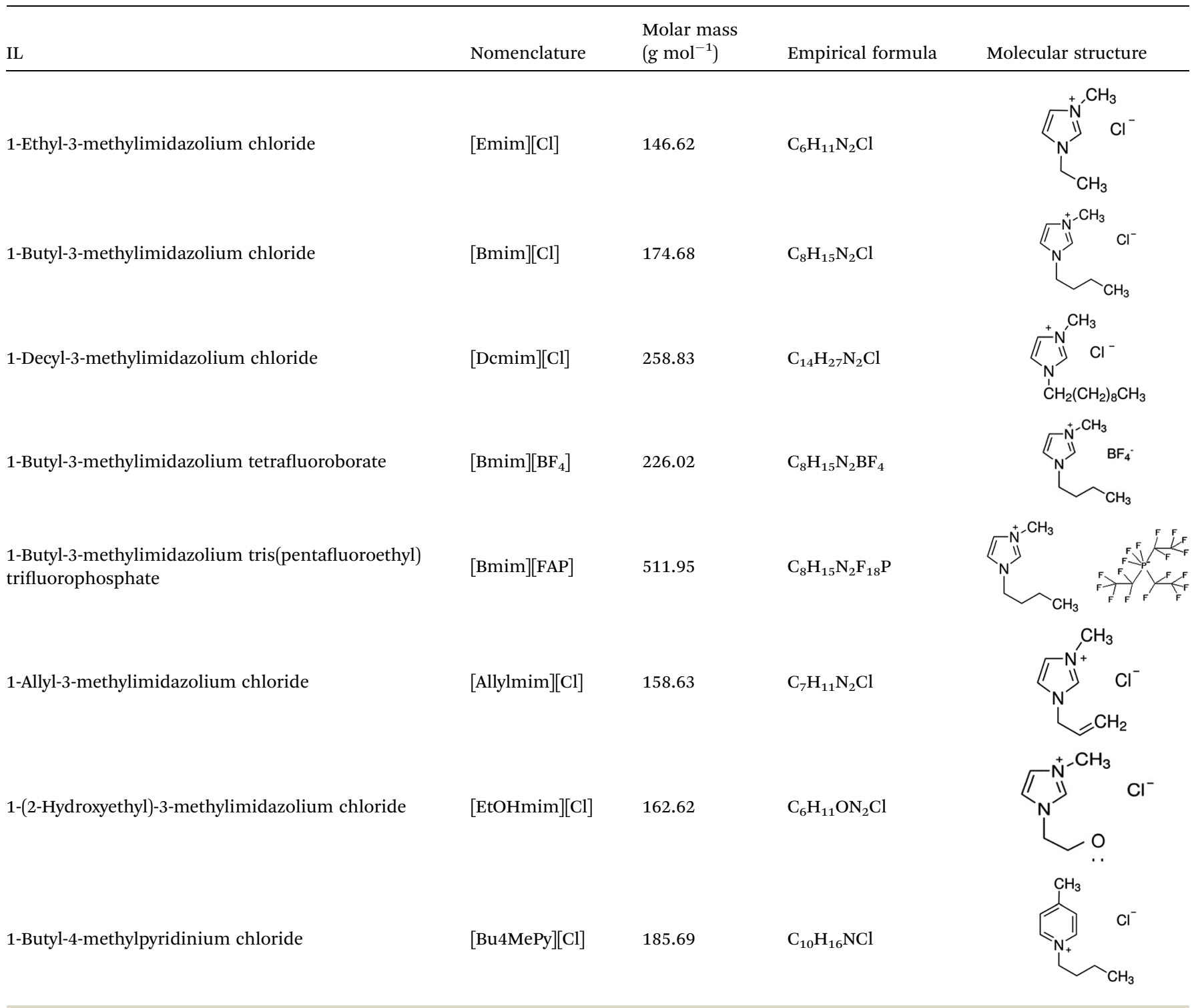

frequency calculations were always carried out to check the existence of a local energy minimum.

\section{Results and discussion}

\section{UV-vis absorption}

Fig. 1 depicts the UV-vis profiles of the ILs at $10 \mathrm{mg} \mathrm{L}^{-1}$ in aqueous solution. As can be seen, all of them show adsorption exclusively within the 200 to $300 \mathrm{~nm}$ range of wavelength, namely in the UV region of the light spectrum. It is clearly seen that most of the ILs analysed absorb light only at wavelengths below $240 \mathrm{~nm}$. Only [Allylmin][Cl], [EtOHmin][Cl] and especially $[\mathrm{Bu} 4 \mathrm{MePy}][\mathrm{Cl}]$ absorb at wavelengths above that value. DFT calculations were performed to complete the analysis of UV-vis absorption of ILs. It is well known that an equilibrium between dissociated ions and ion-pair species of ILs exists in water solutions. ${ }^{\mathbf{4 3 , 4 4}}$ In addition, several works demonstrated that those different ionic species are responsible of in the complex photophysical properties of ILs in solution. ${ }^{45,46}$ Then, current simulations involve "independent ions" and "ion-pair" molecular models (see Fig. S2 in ESI $\dagger$ ). Table 2 collects the calculated Franck-Condon transition energies $\left(\lambda_{\mathrm{abs}}\right)$ for the B3LYP groundstate $\left(\mathrm{S}_{0}\right)$ structures at the TD-DFT first excited-state level $\left(\mathrm{S}_{1}\right)$. As can be seen, independent $[\mathrm{Emim}]^{+},[\mathrm{Bmim}]^{+}$and $[\mathrm{Dmim}]^{+}$ present calculated $\lambda_{\text {abs }}$ at near $200 \mathrm{~nm}$, whereas the absorption of $[\mathrm{Emim}][\mathrm{Cl}],[\mathrm{Bmim}][\mathrm{Cl}]$ and $[\mathrm{Dcmim}][\mathrm{Cl}]$ is similarly predicted in the region of $270 \mathrm{~nm}$ (the complete calculated UVvisible spectra are available in Fig. S3 of ESI†). These results indicate that the equilibrium of ILs based on the hydrophilic chloride anion in water is significantly displaced toward the dissociated ions, in good agreement with experimental observations. ${ }^{43,44}$ In the case of $\left[\mathrm{Bmim}^{4}\left[\mathrm{BF}_{4}\right]\right.$ and $[\mathrm{Bmim}][\mathrm{FAP}]$ both "independent ions" and "ion-pair" molecular models predict $\lambda_{\text {abs }}$ values near $200 \mathrm{~nm}$, in correspondence with the UV-vis spectra of these ILs. However, it should be emphasized that experimental evidences ${ }^{\mathbf{4 3 , 4 5 - 4 7}}$ and calculations ${ }^{48}$ indicate an 

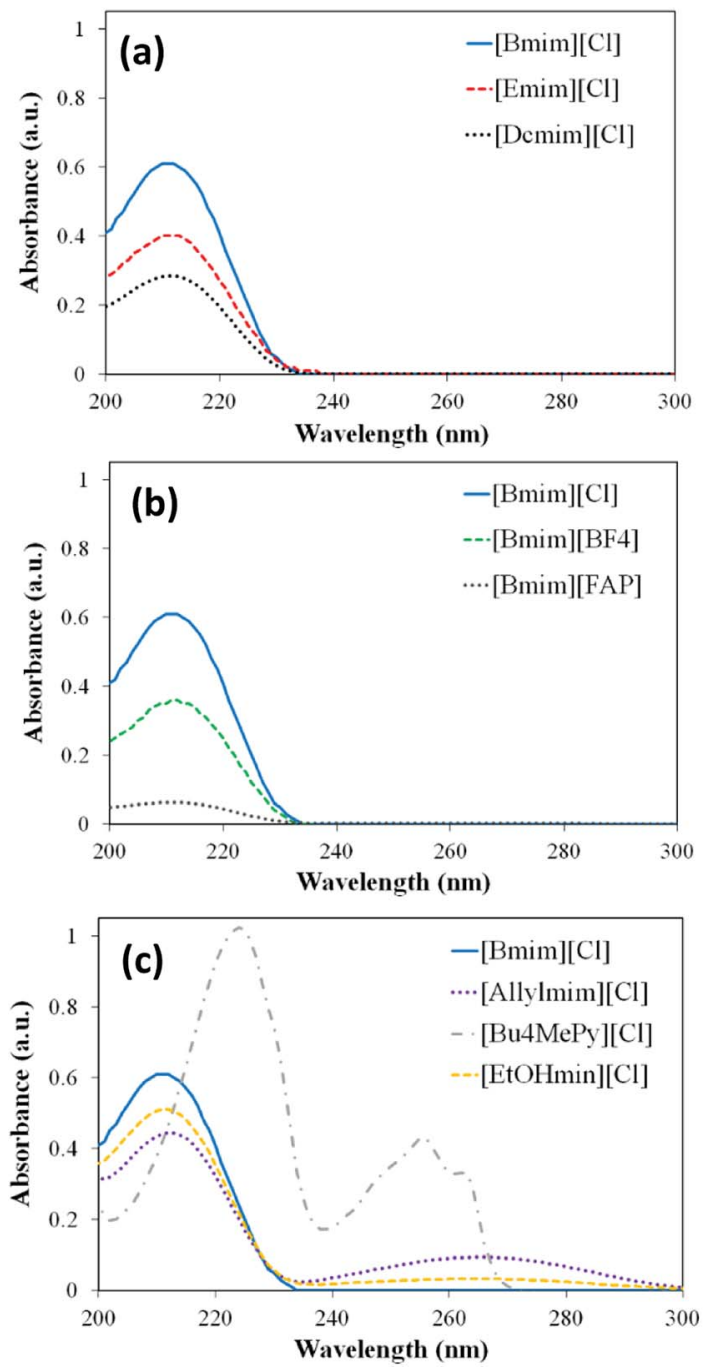

Fig. 1 UV-vis profiles of the different ILs $\left(10 \mathrm{mg} \mathrm{L}^{-1}\right)$ in aqueous solution.

increasing concentration of ion-pair species when increasing anion hydrophobicity (see octanol-water partition coefficients, $K_{\mathrm{OW}}$, in Table 2) in the order $[\mathrm{FAP}]>\left[\mathrm{BF}_{4}\right]>[\mathrm{Cl}]$. Finally, the presence of functional groups (allyl, hydroxyl) does not modify the absorption of the solvated cation $\left(\lambda_{\text {abs }} \sim 200 \mathrm{~nm}\right)$, although it

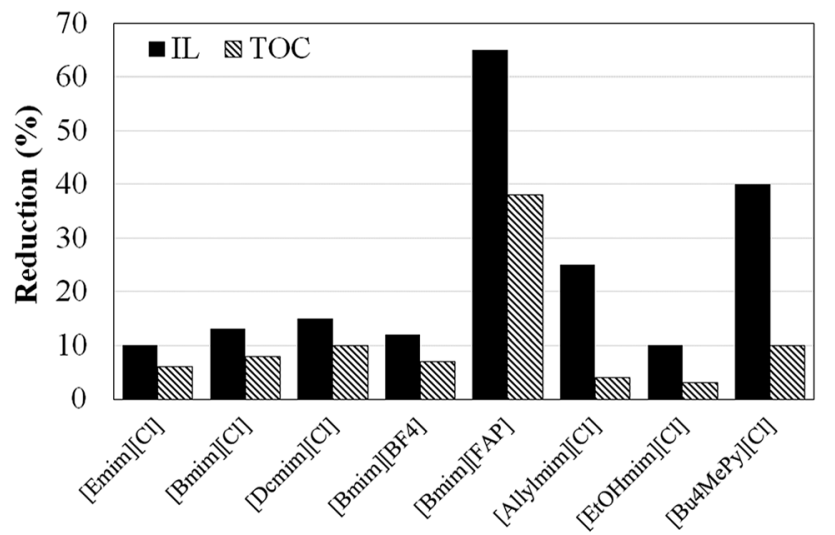

Fig. 2 Reduction of IL concentration and TOC after 10 hours of solar irradiation $\left(450 \mathrm{~W} \mathrm{~m}^{-2}\right.$ ) in the absence of the photocatalyst (photolysis experiments).

seems to affect the equilibrium of IL pairs in water, being observed absorbance in the region of $370 \mathrm{~nm}$, corresponding to ion-pair excitation energies. The pyridinium-based IL presents clearly different experimental spectra, with two intense absorption bands with maxima at 255 and $225 \mathrm{~nm}$. DFT calculations (Fig. S3 of ESI $\dagger$ ) indicate that the concentration of both independent ions and ion-pair species are significant in the case of [Bu4MePy $][\mathrm{Cl}]$.

\section{Photostability tests}

The chemical and thermal stability of ILs has been studied in the literature, ${ }^{49-53}$ although not under solar irradiation, to the best of our knowledge. Fig. 2 summarizes the reduction of the IL concentration and TOC after 10 hours of solar irradiation in the absence of the photocatalyst. As can be seen all the ILs analysed suffer degradation, although in different extent. The ILs with imidazolium-based cation and chloride anion ([Emim][Cl], $[\mathrm{Bmim}][\mathrm{Cl}]$, [Dcmim $][\mathrm{Cl}]$ and [EtOHmim $][\mathrm{Cl}]$ ) show the highest stability, with only 10 to $15 \%$ concentration decrease and TOC reductions below $10 \%$. It can also be observed that the stability increases as the length of the alkyl chain of the imidazolium cation decreases $([\mathrm{Emim}][\mathrm{Cl}]>[\mathrm{Bmim}][\mathrm{Cl}]>[\mathrm{Dcmim}][\mathrm{Cl}])$. The $\mathrm{S}_{0} \rightarrow \mathrm{S}_{1}$ electronic excitation of [Bmim] involves mainly HOMO and LUMO orbitals implying a charge displacement from the

Table 2 Calculated $\mathrm{S}_{0} \rightarrow \mathrm{S}_{1}$ absorption wavelength ( $\lambda_{\text {abs }}$ ). Mülliken charges (q) of carbon atom at 4 position of imidazolium ring in fundamental $\left(S_{0}\right)$ and first excited $\left(S_{1}\right)$ electronic state and octanol-water partition coefficient ( $\left.K_{\mathrm{OW}}\right)$

\begin{tabular}{|c|c|c|c|c|c|c|c|}
\hline \multirow[b]{3}{*}{ Ionic liquid } & \multicolumn{3}{|c|}{ Independents ions $(\mathrm{C}+\mathrm{A})$} & \multicolumn{3}{|c|}{ Ion-pair (CA) } & \multirow[b]{3}{*}{$\log K_{\text {OW }}($ ref. 4$)$} \\
\hline & \multirow[b]{2}{*}{$\lambda_{\mathrm{abs}}(\mathrm{nm})$} & \multicolumn{2}{|l|}{$q_{\text {Mülliken }}$} & \multirow[b]{2}{*}{$\lambda_{\mathrm{abs}}(\mathrm{nm})$} & \multicolumn{2}{|l|}{$q_{\text {Mülliken }}$} & \\
\hline & & $\mathrm{C}_{4}\left(\mathrm{~S}_{0}\right)$ & $\mathrm{C}_{4}\left(\mathrm{~S}_{1}\right)$ & & $\mathrm{C}_{4}\left(\mathrm{~S}_{0}\right)$ & $\mathrm{C}_{4}\left(\mathrm{~S}_{1}\right)$ & \\
\hline$[\mathrm{Emim}][\mathrm{Cl}]$ & 199.9 & -0.092 & -0.061 & 372.3 & -0.146 & -0.215 & -5.4 \\
\hline$[\mathrm{Bmim}][\mathrm{Cl}]$ & 200.8 & -0.094 & -0.069 & 370.3 & -0.187 & -0.260 & -4.4 \\
\hline$[$ Dcmim $][\mathrm{Cl}]$ & $195.9^{\mathrm{a}}$ & -0.081 & -0.147 & 370.7 & -0.102 & -0.197 & -1.2 \\
\hline$[\mathrm{Bmim}]\left[\mathrm{BF}_{4}\right]$ & 200.8 & -0.094 & -0.069 & 197.4 & 0.002 & -0.017 & -2.0 \\
\hline$[\mathrm{Bmim}][\mathrm{FAP}]$ & 200.8 & -0.094 & -0.069 & 218.1 & -0.034 & -0.131 & 5.3 \\
\hline$[$ Allylmim $][\mathrm{Cl}]$ & 227.4 & -0.150 & -0.179 & 373.7 & 0.032 & -0.032 & -5.0 \\
\hline$[$ EtOHmim $][\mathrm{Cl}]$ & 230.3 & -0.027 & -0.021 & 373.8 & -0.106 & -0.183 & 1.4 \\
\hline$[\mathrm{Bu} 4 \mathrm{MePy}][\mathrm{Cl}]$ & 233.4 & - & - & 756.6 & - & - & -3.8 \\
\hline
\end{tabular}


C4-C5 bond to the $\mathrm{N}$ atoms of the imidazolium ring (See Fig. S4 in ESI $\dagger$ ). Therefore, light absorption to first excited state reduces the electronic density of C4 and C5 atoms (see Mülliken charges in Table 2), thus becoming more active sites for oxidation. On the other hand, the anions have a more pronounced effect on the solar light stability of the ILs. [Bmim] [FAP] show little stability under solar light with IL and TOC reductions higher than 60 and 35\%, respectively, after $10 \mathrm{~h}$. As indicated before, [FAP] anion presents a strong hydrophobic character and, consequently, the concentration of ion-pair species in [Bmim][FAP] is expected to be much higher than in $[\mathrm{Bmim}][\mathrm{Cl}]$. Therefore, the lower light stability of this IL must be ascribed to the ion-pair species, which present a clearly different photophysical behaviour than the solvated ions, as shown by the potential energy surfaces of $S_{1}$ and $S_{0}$ states of Fig. 3 and the electrostatic potential surface in Fig. S5 of ESI, $\uparrow$ obtained from DFT calculations. The introduction of the double bond in the alkyl chain of the cation ([Allylmim]) notably decreases the stability of the IL under solar light. Even more noticeable is the stability decrease associated to the pyridinium cation. These results are in agreement with those previously reported by Morawaski et al. ${ }^{33}$ for the degradation of different ILs under UV light in the presence of $\mathrm{TiO}_{2}$. The relatively low stability of [Allylmim $][\mathrm{Cl}]$ and $[\mathrm{Bu} 4 \mathrm{MePy}][\mathrm{Cl}]$ may be also related to the higher concentration of ion-pair species in aqueous solution, evidenced by the spectroscopic analyses and DFT calculations. On the other hand, $[\mathrm{Bmim}]\left[\mathrm{BF}_{4}\right]$ and $[\mathrm{EtOHmim}]$ [Cl] show high light stability, similar to that found for [Bmim] [Cl], despite other behaviour would be expected from the experimental and calculated spectroscopic results.

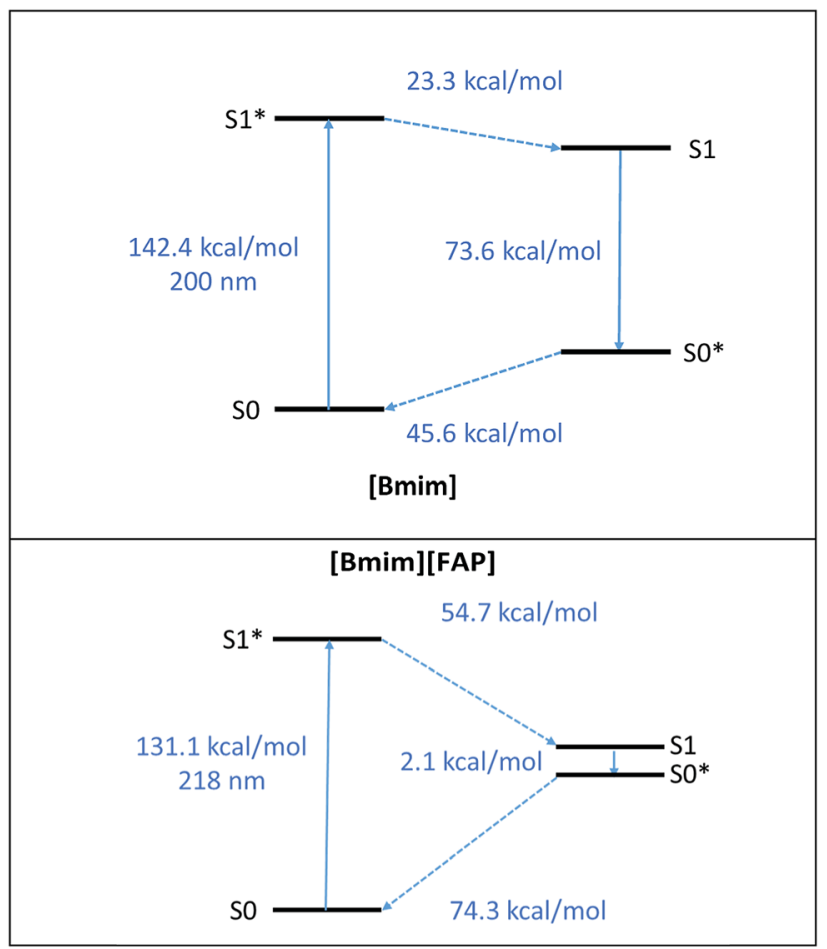

Fig. 3 Potential energy surfaces of fundamental $\left(S_{0}\right)$ and first excited $\left(\mathrm{S}_{1}\right)$ electronic state of [Bmim] cation and [Bmim][FAP] ionic pair calculated at TD-B3LYP/6-311++G** computational level.

\section{Photocatalytic degradation}

Photocatalytic experiments were performed firstly with those ILs based on imidazolium cations with the same anion and different length of the cationic alkyl chain. It is known that photocatalytic reaction occurs on the surface of the catalyst, where the reactants are adsorbed. Thus, prior to irradiation, adsorption tests were carried out in dark for 2 hours (see Fig. S6 of ESI $\dagger$ ). In these conditions, only [Dcmim][Cl] was significantly adsorbed $(\approx 25 \%)$ on $\mathrm{TiO}_{2}$ while the two other ILs showed negligible adsorption. This can be explained by the higher interaction of the long aliphatic chain of [Dcmim] [Cl] with the titania surface, in good agreement with the previous study of Farooq et al. ${ }^{54}$

Fig. $4 \mathrm{a}$ and $\mathrm{b}$ show the evolution of IL concentration and TOC upon the irradiation time in the presence of $\mathrm{TiO}_{2}$ (75 $\mathrm{mg} \mathrm{L}^{-1}$ ) for ILs with the same anion ([Cl]) and different length of the alkyl chain of the cation (imidazolium-based). Much higher degradation was achieved compared with the previous photolysis experiments, both in terms of IL and TOC conversions. Despite the relatively low $\mathrm{TiO}_{2}$ loading $\left(75 \mathrm{mg} \mathrm{L}^{-1}\right)$ the ILs were completely converted in relatively low time. The TOC evolution does not follow the same profile than IL concentration, thus suggesting the formation of intermediate and final by-products. Nevertheless, fairly high mineralization levels ( $80 \%$ in some cases) were achieved. These results probe
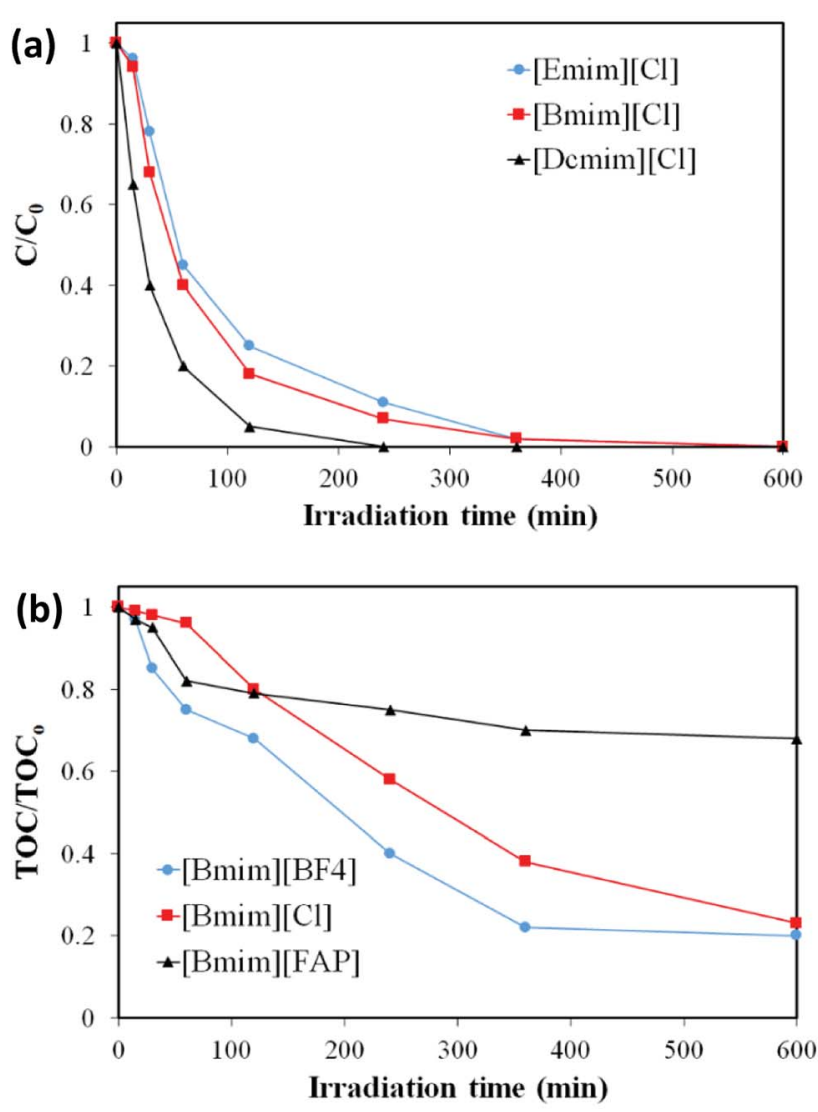

Fig. 4 Evolution of (a) IL concentration and (b) TOC upon irradiation time in the presence of $\mathrm{TiO}_{2}$ for ILs with the same anion ([Cl]) and different length of the cationic alkyl chain (imidazolium-based). 
for the first time that photocatalysis under solar light could be an effective method for the degradation of ILs in water. It can be also observed the effect of the length of the cationic alkyl chain on the degradation rates of the ILs. As can be seen, the longer the alkyl chain the faster degradation rate $([\mathrm{Dcmim}]>[\mathrm{Bmim}]>$ [Emim]). After $60 \mathrm{~min}$, [Dcmim] [Cl] undergoes 80\% conversion whereas for $[\mathrm{Emim}][\mathrm{Cl}]$ only about $55 \%$ was reached. It is known that longer alkyl cations show higher oxidability. ${ }^{55}$ The remaining TOC evidences the presence of some residual byproducts refractory to photocatalytic degradation under solar light in our working conditions.

Despite the literature establishes the importance of the anion in the properties and reactivities of the ILs, very few works have studied the effect of the anion in photocatalytic degradation. Fig. 5a and b depict the evolution of IL concentration and TOC upon irradiation time in the presence of $\mathrm{TiO}_{2}$ for ILs with the same cation ([Bmim]) and different anions. As indicated before, adsorption was negligible (Fig. S5 $\dagger$ ). Again, it is observed that the three ILs were completely converted regardless of the anion analysed. The anion shows little effect on the rate of degradation, being slightly higher for the ILs containing $\left[\mathrm{BF}_{4}\right]$ and $[\mathrm{Cl}]$ anions than for the one with [FAP]. However, more important differences can be seen relative to TOC. The TOC reduction for $[\mathrm{Bmim}]\left[\mathrm{BF}_{4}\right]$ and $[\mathrm{Bmim}][\mathrm{Cl}]$ follows quite similar trend, with about $80 \%$ after the 10 hours of experiments, whereas much lower mineralization is observed in the case of
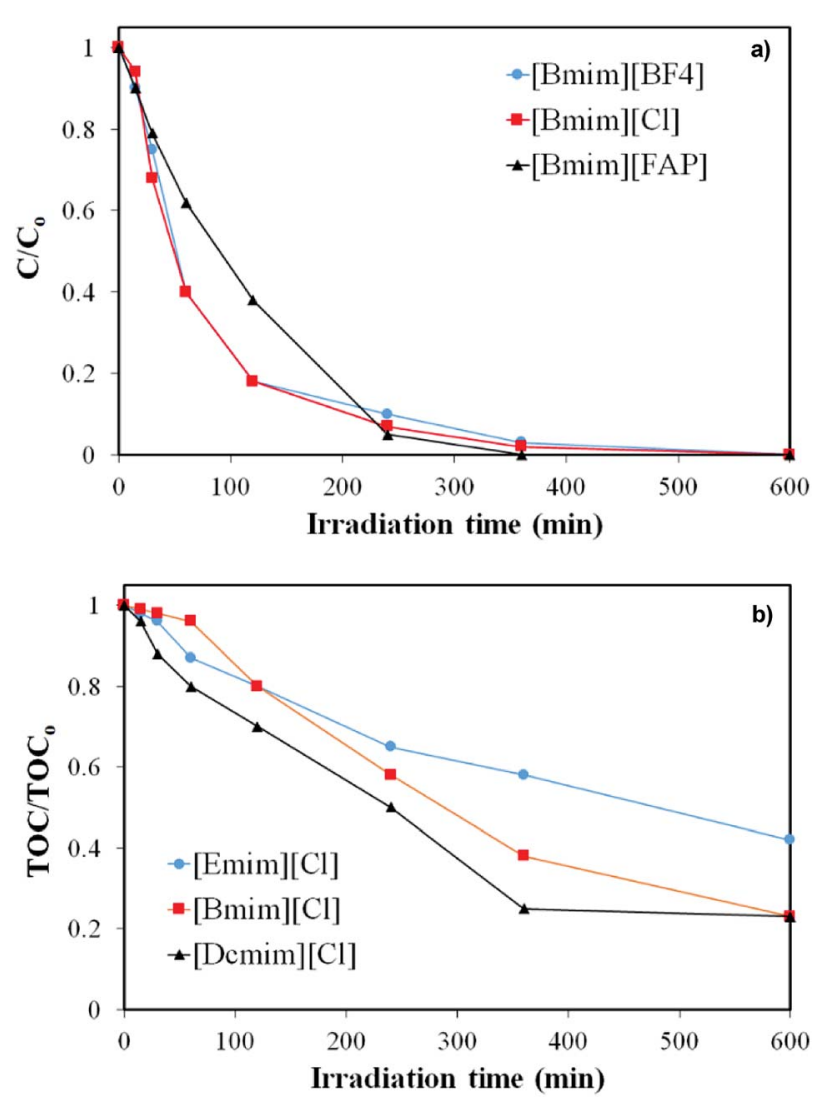

Fig. 5 Evolution of (a) IL concentration and (b) TOC upon irradiation time in the presence of $\mathrm{TiO}_{2}$ for imidazolium-based ILs with different anions.
[Bmim $][\mathrm{FAP}]$. It should be noted that, in this IL, TOC is associated to both [Bmim] cation and [FAP] anion, since both contain organic carbon, in contrast to the ILs with [Cl] or $\left[\mathrm{BF}_{4}\right]$ anions. Meanwhile the IL concentration was measured through the absorbance of the heterocyclic cation. Therefore, the low TOC reduction in the case of [Bmim] [FAP] can be attributed to negligible degradation of the [FAP] anion under solar light irradiation in presence of $\mathrm{TiO}_{2}$.

The effect of the type of cation on the photocatalytic degradation of the ILs was also analysed. Fig. 6 represents the evolution of IL concentration and TOC upon irradiation time in the presence of $\mathrm{TiO}_{2}$ for different ILs with the same anion $([\mathrm{Cl}])$ and different cations. All these ILs were completely converted with comparable final TOC reductions within $65-80 \%$. The degradation rate follows the order $[\mathrm{Bu} 4 \mathrm{MePy}]>[$ Allylmim $] \approx$ $[\mathrm{Bmim}]>$ [EtOHmim $]$. These results indicate that the pyridinum-based IL is easier to degrade that the imidazoliumbased ones, being [Bu4MePy] [Cl] the more reactive IL among those tested. The similar results with the ILs containing [Allyl$\mathrm{mim}]$ and [Bmim] cations indicate that the presence of a double bond in the aliphatic chain does not affect to photodegradation, opposite to the observed for the stability under solar light. Finally, it is interesting that the presence of an $\mathrm{OH}$ group in the alkyl chain reduces the susceptibility of the imidazolium-based ILs to photocatalytic degradation under solar light.

Regarding the remaining TOC, Fig. 7 shows the time-course of carboxylic acids from the solar photocatalytic degradation of
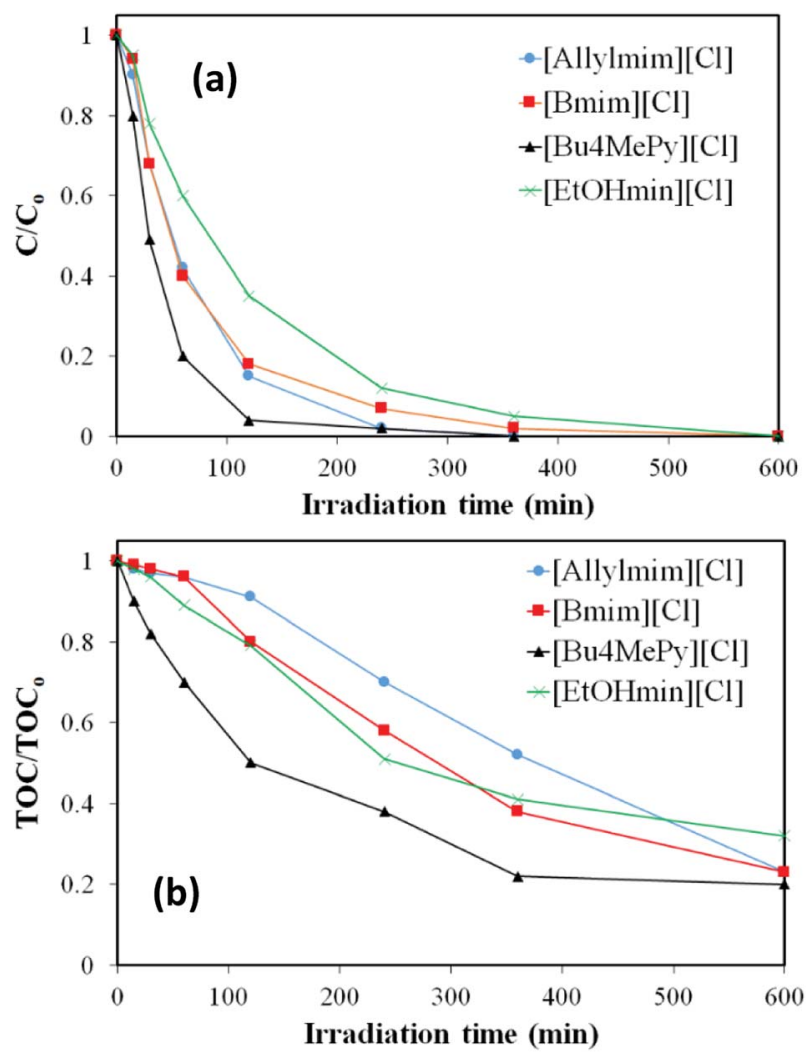

Fig. 6 Evolution of (a) IL concentration and (b) TOC upon irradiation time in the presence of $\mathrm{TiO}_{2}$ for ILs with the same anion ([Cl]) and different types of cations. 
$[\mathrm{Bmim}][\mathrm{Cl}]$ and $[\mathrm{Bu} 4 \mathrm{MePy}][\mathrm{Cl}]$. These results show the formation of formic, acetic and malonic acids, in addition to very low amounts of oxalic acid, as residual by-products from both ILs. It is interesting to notice that the formation of these short-chain organic acids starts in both cases once the IL conversion reached about $80 \%$, suggesting that the breakdown of those ILs occurs in several steps. To the best of our knowledge, there are not works dealing with the identification of by-products from solar photocatalytic degradation of ILs but some works have reported on that issue using Fenton oxidation. ${ }^{22,24}$ Authors described the formation of hydroxylated by-products upon the first step of the process, which are further oxidized by $\mathrm{OH}$ radicals yielding short-chain organic acids like the ones identified in our work. It has to be highlighted that malonic and acetic acids are the most refractory by-products in our case. It is also interesting to check the different evolution of these organic acids for each IL studied. The evolution of formic and acetic acids shows a maximum at $6 \mathrm{~h}$ of irradiation in the case of $[\mathrm{Bmim}][\mathrm{Cl}]$ that it found for [Bu4MePy$][\mathrm{Cl}]$. Complimentary, the carbon balance of the degradation of both $[\mathrm{Bmim}][\mathrm{Cl}]$ and [Bu4MePy][Cl] ILs has been included in ESI (Fig. S7 $\dagger$ ). This figure represents the evolution of TOC, IL, organic acids and other non-identified products, all in terms of carbon. The nonidentified products were estimated from the difference among the TOC measured and the TOC calculated from IL and the identified reaction products. It is noteworthy that upon
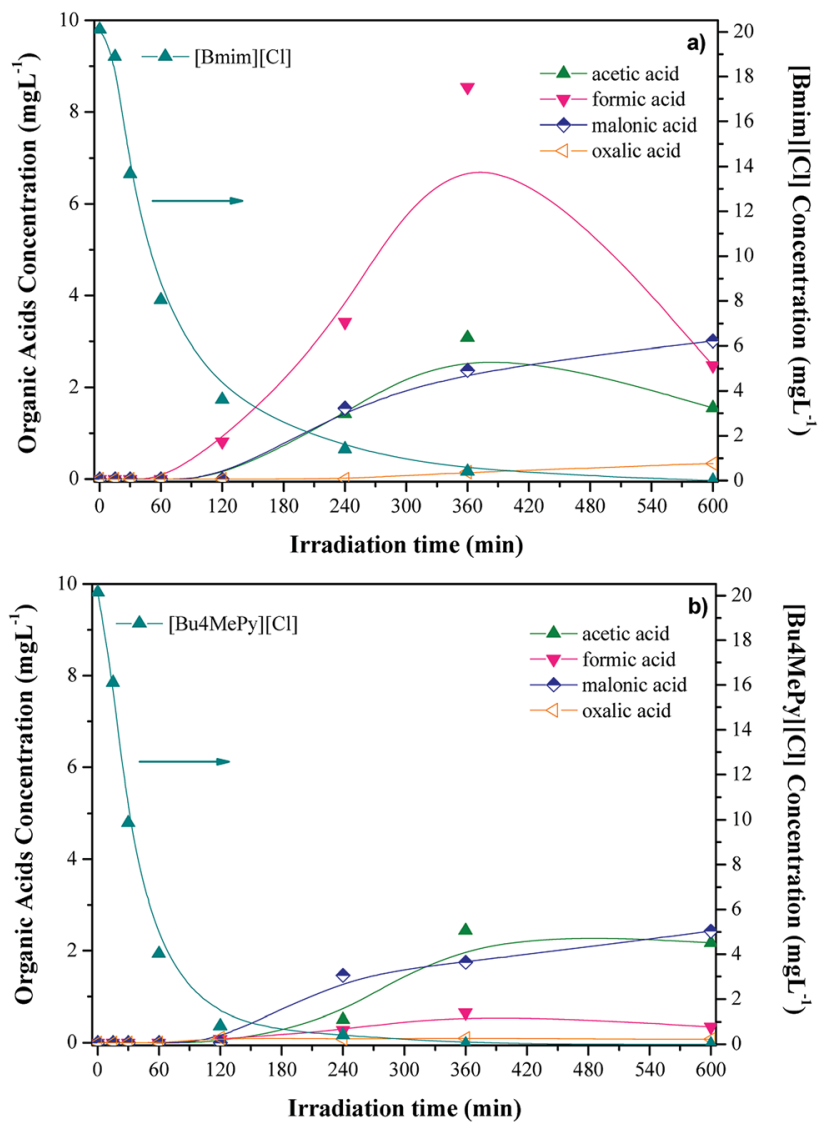

Fig. 7 Evolution of ILs and organic upon photocatalytic oxidation with $\mathrm{TiO}_{2}$ of $[\mathrm{Bmim}][\mathrm{Cl}]$ (a) and [Bu4MePy][Cl] (b). irradiation times of $4 \mathrm{~h}$ although the IL disappeared from the solution the mineralization rate was considerably low, remaining in solution a high amount of unidentified by-products. Nevertheless, these non-identified byproducts were almost removed after $10 \mathrm{~h}$ of reaction, transforming both $\mathrm{CO}_{2}$ and organic acids, achieving mineralization rates close to $80 \%$. These results prove the significant application of solar photocatalysis for the removal of ILs in water.

\section{Conclusions}

The stability of different ILs and their photocatalytic degradation under solar light with $\mathrm{TiO}_{2}$ in aqueous solution $\left(20 \mathrm{mg} \mathrm{L}^{-1}\right)$ have been studied. All ILs undergo degradation upon solar light irradiation, although in different extent. Imidazolium-based ILs with hydrophilic anion (chloride) and shorter alkyl chains are more stable than the ones with hydrophobic anion or structural features (kind of cation, functional groups) increasing the concentration of ion-pair species in water.

Regarding photocatalytic breakdown under solar light, despite the relatively low $\mathrm{TiO}_{2}$ concentration $\left(75 \mathrm{mg} \mathrm{L}^{-1}\right)$ used, all the ILs tested were completely converted. Furthermore, except for the IL with [FAP] anion, the TOC removal is also relatively high, which indicates a high mineralization. These results probe for the first time that photocatalysis under solar light could be a feasible method for the removal of ILs from water. The ILs with longer alkyl chains, are more susceptible to photocatalytic degradation, so that the following order can be stablished: $([$ Dcmim $]>[$ Bmim $]>[$ Emim $])$. The anion has shown little effect on the rate and extent of degradation. Looking at the type of cation, IL degradation follows the order [Bu4MePy] > $[$ Allylmim $] \approx[$ Bmim $]>[$ EtOHmim $]$.

\section{Conflicts of interest}

There are no conflicts to declare.

\section{Acknowledgements}

The authors acknowledge the financial support from Spanish MINECO (projects CTQ2013-41963-R and CTQ2016-78576-R) and Comunidad Autónoma de Madrid (project S2013/MAE2800). We are very grateful to Centro de Computación Científica de la Universidad Autónoma de Madrid for computational facilities.

\section{References}

1 J. F. Brennecke and E. J. Maginn, AIChE J., 2001, 47, 23842389.

2 R. D. Rogers and K. R. Seddon, Science, 2003, 302, 792-793.

3 N. V. Plechkova and K. R. Seddon, Chem. Soc. Rev., 2008, 37, 123-150.

4 J. P. Hallett and T. Welton, Chem. Rev., 2011, 111, 3508-3576.

5 J. Bedia, J. Palomar, M. Gonzalez-Miquel, F. Rodriguez and J. J. Rodriguez, Sep. Purif. Technol., 2010, 95, 188-195. 
6 A. Romero, A. Santos, J. Tojo and A. Rodríguez, J. Hazard. Mater., 2008, 151, 268-273.

7 S. Wu, L. Zeng, C. Wang, Y. Yang, W. Zhou, F. Li and Z. Tan, J. Hazard. Mater., 2018, 348, 1-9.

8 R. Biczak, B. Pawłowska, P. Bałczewski and P. Rychter, J. Hazard. Mater., 2014, 274, 181-190.

9 L. Zhang, W. Cao, P. J. J. Alvarez, X. Qu, H. Fu, S. Zheng, Z. Xu and D. Zhu, Appl. Surf. Sci., 2018, 440, 821-829.

10 J. Lemus, C. Moya, M. A. Gilarranz, J. J Rodriguez and J. Palomar, J. Environ. Chem. Eng., 2017, 5, 5347-5351.

11 S. Hassan and T. Yasin, Int. J. Environ. Sci. Technol., 2015, 12, 2711-2722.

12 C. M. S. S. Neves, J. Lemus, M. G. Freire, J. Palomar and J. A. P. Coutinho, Chem. Eng. J., 2014, 252, 305-310.

13 L. Li, Y. Wang and X. Qi, RSC Adv., 2015, 5, 41352-41358.

14 S. B. Choi, S. W. Won and Y.-S. Yun, Chem. Eng. J., 2013, 214, 78-82.

15 C. M. S. S. Neves, M. G. Freire and J. A. P. Coutinho, RSC Adv., 2012, 2, 10882-10890.

16 L. Reinert, K. Batouche, J.-M. Lévêque, F. Muller, J.-M. Bény, B. Kebabi and L. Duclaux, Chem. Eng. J., 2012, 209, 13-19.

17 L. Zhang, J. Zhang, H. Fu, H. Zhang, H. Liu, Y. Wan, S. Zheng and Z. Xu, Microporous Mesoporous Mater., 2018, 260, 59-69.

18 J. Lemus, J. Palomar, F. Heras, M. A. Gilarranz and J. J. Rodriguez, Sep. Purif. Technol., 2012, 97, 11-19.

19 J. D. Oxley, T. Prozorov and K. S. Suslick, J. Am. Chem. Soc., 2003, 125, 11138-11139.

20 E. M. Siedlecka, S. Stolte, M. Gołębiowski, A. Nienstedt, P. Stepnowski and J. Thöming, Sep. Purif. Technol., 2012, 101, 26-33.

21 E. M. Siedlecka, A. Fabianska, S. Stolte, A. Nienstedt, T. Ossowski, P. Stepnowski and J. Thöming, Chem. Eng. J., 2013, 8, 5560-5574.

22 E. Gomez-Herrero, M. Tobajas, A. Polo, J. J. Rodriguez and A. F. Mohedano, Environ. Sci. Pollut. Res., 2018, 25, 3493034937.

23 E. M. Siedlecka, W. Mrozik, Z. Kaczyński and P. Stepnowski, J. Hazard. Mater., 2008, 154, 893-900.

24 M. Munoz, C. M. Domínguez, Z. M. De Pedro, A. Quintanilla, J. A. Casas and J. J. Rodriguez, Catal. Today, 2015, 240, 16-21.

25 M. Munoz, C. M. Domínguez, Z. M. De Pedro, A. Quintanilla, J. A. Casas, S. P. M. Ventura and J. A. P. Coutinho, Sep. Purif. Technol., 2015, 150, 252-256.

26 H. Zhou, P. Lv, Y. Shen, J. Wang and J. Fan, Water Res., 2013, 47, 3514-3522.

27 H. Zhou, Y. Shen, P. Lv, J. Wang and P. Li, J. Hazard. Mater., 2015, 284, 241-252.

28 I. F. Mena, S. Cotillas, E. Díaz, C. Sáez, A. F. Mohedano and M. A. Rodrigo, J. Hazard. Mater., 2018, DOI: 10.1016/ j.jhazmat.2017.12. 015.

29 V. Poza-Nogueiras, M. Arellano, E. Rosales, M. Pazos, E. González-Romero and M. A. Sanromán, Chemosphere, 2018, 199, 68-75.

30 E. Bocos, M. Pazos and M. A. Sanromán, RSC Adv., 2016, 6, 1958-1965.
31 E. Bocos, E. González-Romero, M. Pazos and M. A. Sanromán, Chem. Eng. J., 2017, 318, 19-28.

32 P. Stepnowski and A. Zaleska, J. Photochem. Photobiol., A, 2005, 170, 45-50.

33 A. W. Morawski, M. Janus, I. Goc-maciejewska, A. Syguda and J. Pernak, Pol. J. Chem., 2005, 79, 1929-1935.

34 T. Itakura, K. Hirata, M. Aoki, R. Sasai, H. Yoshida and H. Itoh, Environ. Chem. Lett., 2009, 7, 343-345.

35 P. Calza, D. Fabbri, G. Noé, V. Santoro and C. Medana, J. Hazard. Mater., 2018, 341, 55-65.

36 A. C. Sola, D. Garzón Sousa, J. Araña, O. González Díaz, J. M. Doña Rodríguez, P. Ramírez de la Piscina and N. Homs, Catal. Today, 2017, 266, 53-61.

37 C. Belver, M. Hinojosa, J. Bedia, M. Tobajas, M. A. Alvarez, V. Rodríguez-González and J. J. Rodriguez, Materials, 2017, 10, 960.

38 C. Belver, J. Bedia and J. J. Rodriguez, J. Hazard. Mater., 2017, 322, 233-242.

39 C. Belver, J. Bedia and J. J. Rodriguez, Appl. Catal., B, 2015, 176-177, 278-287.

40 M. J. Frish, et al., Gaussian 09, Inc., Wallingford, CT, USA, 2009.

41 A. D. Becke, Phys. Rev. A, 1988, 38, 3098-3100.

42 C. Adamo and D. Jacquemin, Chem. Soc. Rev., 2013, 42, 845856.

43 H. K. Stassen, R. Ludwig, A. Wulf and J. Dupont, Chem. - Eur. J., 2015, 21, 8324-8355.

44 W. Li, Z. Zhang, B. Han, S. Hu, Y. Xie and G. Yang, J. Phys. Chem. B, 2007, 111, 6452-6456.

45 E. Binetti, A. Panniello, L. Triggiani, R. Tommasi, A. Agostiano, M. L. Curri and M. Striccoli, J. Phys. Chem. B, 2012, 116, 3512-3518.

46 S. Cha, T. Shim, Y. Ouchi and D. Kim, J. Phys. Chem. B, 2013, 117, 10818-10825.

47 A. Guleria, A. K. Singh and S. Adhikari, Phys. Chem. Chem. Phys., 2015, 17, 11053-11061.

48 J. Palomar, V. R. Ferro, M. A. Gilarranz and J. J. Rodriguez, J. Phys. Chem. B, 2007, 111, 168-180.

49 J. J. Parajó, M. Villanueva, I. Otero, J. Fernández and J. Salgado, J. Chem. Thermodyn., 2018, 116, 185-196.

50 J. J. Parajó, T. Teijeira, J. Fernández, J. Salgado and M. Villanueva, J. Chem. Thermodyn., 2017, 112, 105-113.

51 P. Schmitz, M. Kolek, M. Pyschik, K. Jalkanen, S. Nowak, M. Winter and P. Bieker, ChemistrySelect, 2017, 2, 60526056.

52 M. Kosmulski, J. Gustafsson and J. B. Rosenholm, Thermochim. Acta, 2004, 412, 47-53.

53 S. Sowmiah, V. Srinivasadesikan, M.-C. Tseng and Y.-H. Chu, Molecules, 2009, 14, 3780-3813.

54 A. Farooq, L. Reinert, J.-M. Levêque, N. Papaiconomou, N. Irfan and L. Duclaux, Microporous Mesoporous Mater., 2012, 158, 55-63.

55 M. Czerwicka, S. Stolte, A. Müller, E. M. Siedlecka, M. Gołebiowski, J. Kumirska and P. Stepnowski, J. Hazard. Mater., 2009, 171, 478-483. 